\title{
DISTRIBUIÇÃO ESPACIAL DAS CHUVAS E BALANÇO HÍDRICO NA MICRORREGIÃO DE PATROCÍNIO
}

\author{
UNIPAM \\ Isabela Cristina Hypólito - \\ UNIPAM \\ Arthur Damon Santos - \\ UNIPAM
}

Ana Carolina Crestani - anaacarolinac1 @ gmail.com

Damaris de Souza Nascimento - adamarisdenascimento@gmail.com

UNIPAM

Gustavo-@unipam.edu.br

UNIPAM 


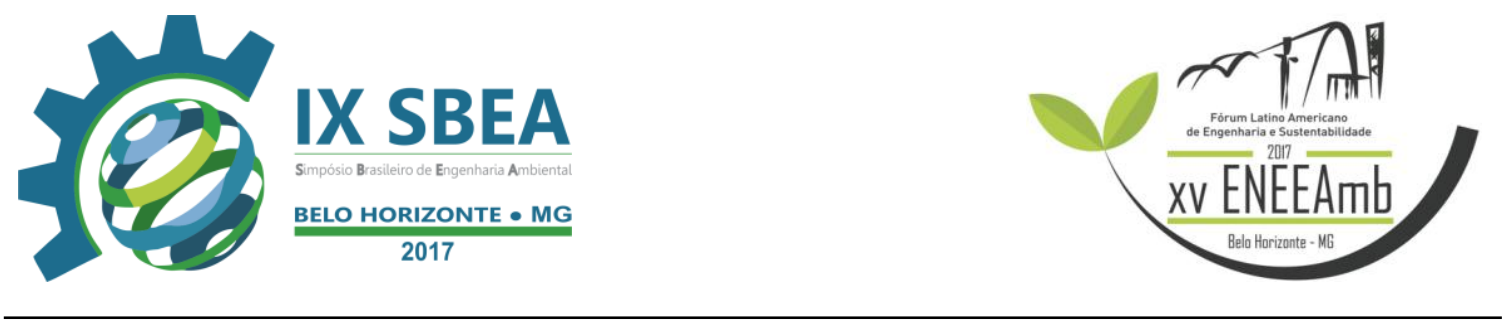

\section{RESUMO}

O município de Patrocínio é um dos grandes produtores de café do país, com isso, o estudo do índice pluviométrico se faz necessário para que seja possível um melhor planejamento das atividades cafeicultoras. Foram utilizadas as estações de Patrocínio, Iraí de Minas, Santa Juliana, Araxá, Ibiá, Carmo do Paranaíba, Monte Carmelo, Patos de Minas, Serra do Salitre e Coromandel, totalizando 10 (dez) estações analisadas para a realização do estudo. Utilizou-se os dados de índice pluviométrico dessas estações dos anos de 1991 a 2015, perfazendo um período de 24 anos. O método utilizado para realização do balanço hídrico foi o desenvolvido por Thornthwaite, Mather (1955).

Palavras-chave: Balaço Hídrico; Microrregião Patrocínio; Pluviosidade; Produção Cafeeira; Chuva; Município; Índice Pluviométrico; Déficit; Excedente; Altitude; Alto Paranaíba.

\section{INTRODUÇÃO/OBJETIVO}

O balanço hídrico climatológico pode ser utilizado para quantificar a disponibilidade hídrica de uma região. Sendo assim, é possível demonstrar as deficiências hídricas através da análise dos índices de precipitação pluvial e evapotranspiração potencial. A evapotranspiração é de suma importância, pois através da mesma, pode-se fazer o cálculo e o acompanhamento da disponibilidade hídrica de uma região, fator essencial para a agricultura local (Pereira et al. 2002; Reichardt, 1985).

Figura 1: Município de Patrocínio

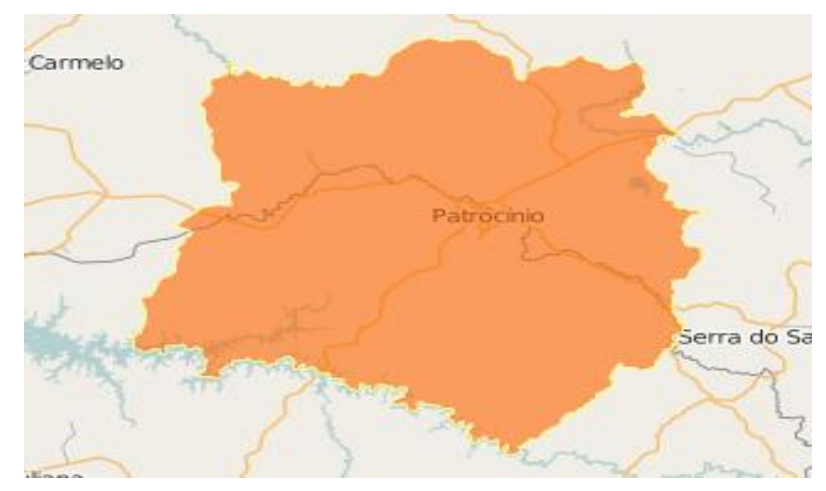




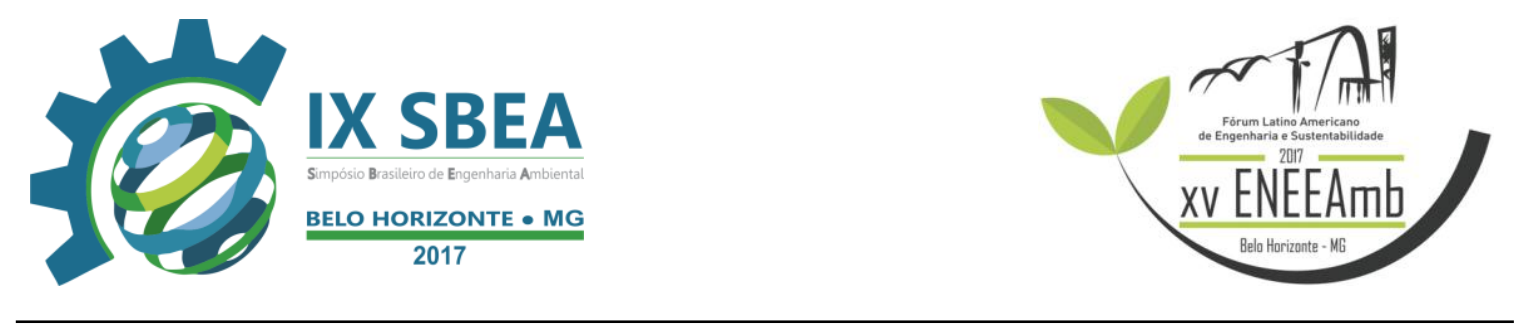

Fonte: IBGE

A cidade de Patrocínio localiza-se nas coordenadas latitude $18^{\circ} 56^{\prime} 39^{\prime \prime}$ de latitude Sul, $46^{\circ} 59^{\prime} 33^{\prime \prime}$ de longitude Oeste (Figura 1), pertence à Mesorregião do Triângulo Mineiro e Alto Paranaíba. A microrregião de Patrocínio abrange os municípios de Abadia dos Dourados, Coromandel, Cruzeiro da Fortaleza, Douradoquara, Estrela do Sul, Grupiara, Iraí de Minas, Monte Carmelo, Romaria e Serra do Salitre. De acordo com o IBGE (2010), possui uma área de 2.874,344 km² (dois milhões, oitocentos e setenta e quatro mil, trezentos e quarenta e quatro quilômetros quadrados) e 84.471 (oitenta e quatro mil, quatrocentos e setenta e um) habitantes.

Patrocínio destaca-se em função da produção de café, possuindo aproximadamente 37 mil (trinta e sete mil hectares) hectares de área plantada de acordo com estimativas do IBGE em 2015. Sabe-se que o sucesso da economia agrícola depende de vários fatores, um deles é o clima, que interfere desde a plantação até a colheita. Por isso é importante que sejam feitos estudos e monitoramentos climatológicos da cidade de Patrocínio.

Levando em consideração a importância econômica que a microrregião de Patrocínio apresenta, o presente trabalho tem por objetivo a realização do balanço hídrico da microrregião de Patrocínio.

\section{METODOLOGIA}

Foram selecionados os dados pluviométricos de um intervalo de 24 (vinte e quatro) anos, de 1991 até 2015. Para que fosse possível analisar o comportamento hídrico nesse período foi realizado um levantamento no site da Agência Nacional das Águas - ANA, e coletados os dados de 10 (dez) municípios.

Esses dados foram retirados das séries históricas presentes na Hidroweb, gerenciada pela Agência Nacional das Águas. O critério usado para o levantamento dos dados dos municípios foi que todos os municípios tivessem a ANA como responsável pelos dados e como operadora responsável a Companhia de Pesquisa de Recursos Minerais (CPRM). 


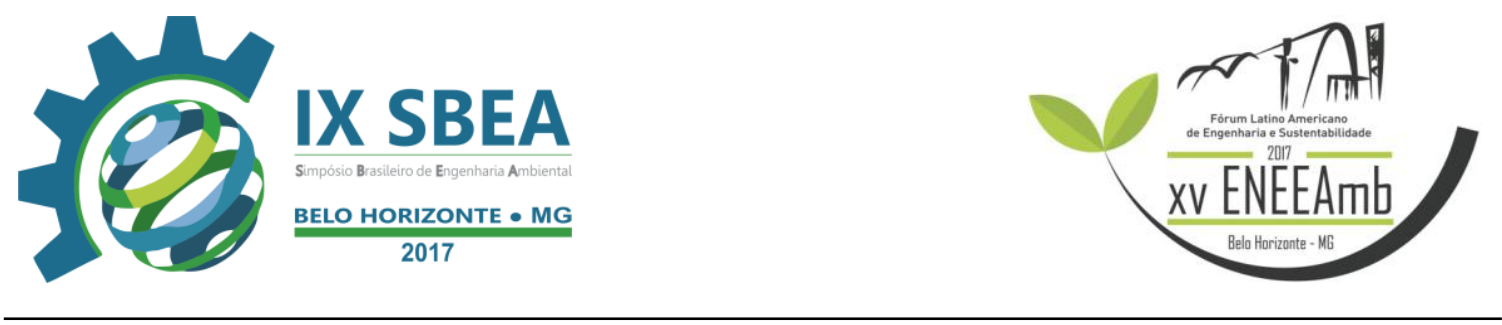

Após o processamento dos dados, foi usado o programa QGIS para o tratamento das informações. Nesse mesmo programa, foram confeccionados todos os mapas apresentados ao logo do trabalho.

Para a realização desse estudo foi utilizado o método desenvolvido por Thornthwaite; Mather (1955) que permite o monitoramento da variação da água armazenada no solo utilizando valores de precipitação, da temperatura e do ar Foi utilizado como base os dados fornecidos pela ANA - Agência Nacional das Águas para criar uma base de dados da Microrregião de Patrocínio.

\section{RESULTADOS E DISCUSSÃO}

Levando em consideração a importância econômica que Patrocínio representa para a região, é essencial a realização do levantamento de dados e informações a respeito do clima local, das precipitações e temperaturas ao longo do ano, assim como da variação histórica desses fatores. Para possibilitar o planejamento e gestão das atividades agrícolas do município.

\subsection{O regime térmico}

A temperatura está diretamente ligada à variação climática e o índice pluviométrico, sendo assim, também é de fundamental importância o seu estudo. A altitude e latitude influenciam diretamente nas características climáticas da Microrregião de Patrocínio (SANTOS, 2005).

De acordo com a figura (Figura 2) pode-se observar que as maiores temperaturas se encontram na parte norte do município, isso ocorre devido ao fato da região norte se encontrar mais próxima da linha do Equador, tendo assim, uma maior incidência de raios solares.

Pode-se observar que a amplitude térmica na Microrregião de Patrocínio é mínima, ao se comparar os meses de maior e menor temperatura. Tendo sua variação equivalente a $4^{\circ} \mathrm{C}$, isso ocorre devido à localização da Microrregião. 


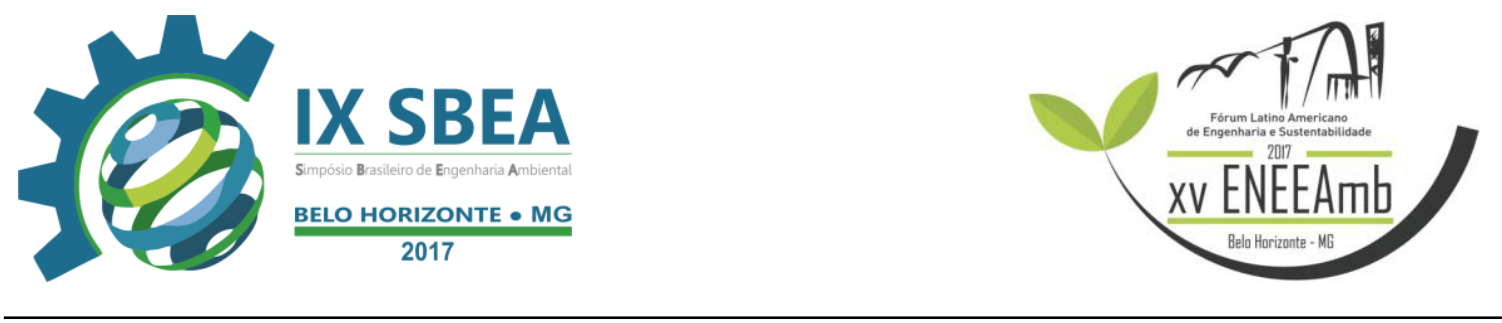

Figura 2: Mapa de Temperatura Média do Município de Patrocínio - MG

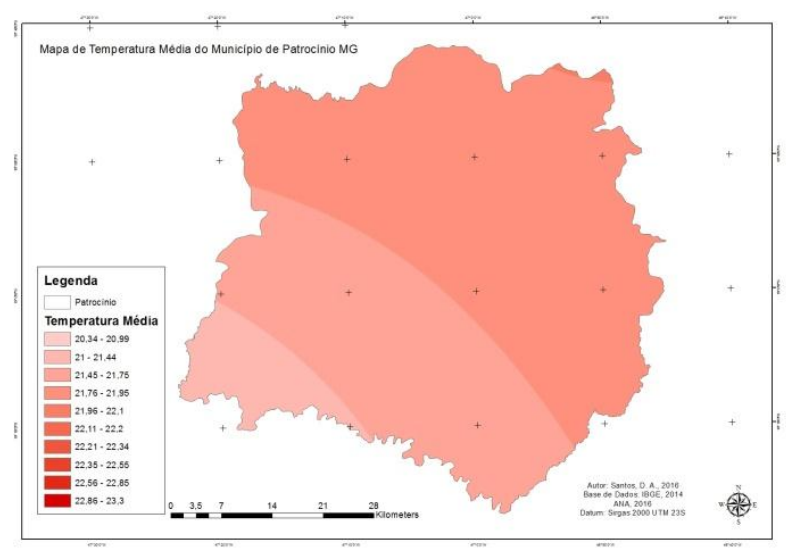

Tendo em vista que a temperatura não é o único fator a ser considerado para determinar quais culturas seriam aptas para determinada região, faz-se necessário a análise de outros fatores para que se chegue a tal conclusão. Mas as características térmicas observadas na Microrregião de Patrocínio indicam que a mesma oferece condições consideradas ideais para o cultivo do café, o que explicaria a grande quantidade de hectares plantados dessa cultura no município.

\subsection{O regime pluviométrico}

Segundo a classificação climática de Köppen-Geiger que foi proposta por Köppen em 1900 e aprimorada nos anos seguintes com a ajuda de Geiger e adaptada por SETZER(1966), a microrregião de Patrocínio possui um clima tropical, com estação seca.

Figura 3: Mapa de Precipitação Média do Município de Patrocínio - MG 

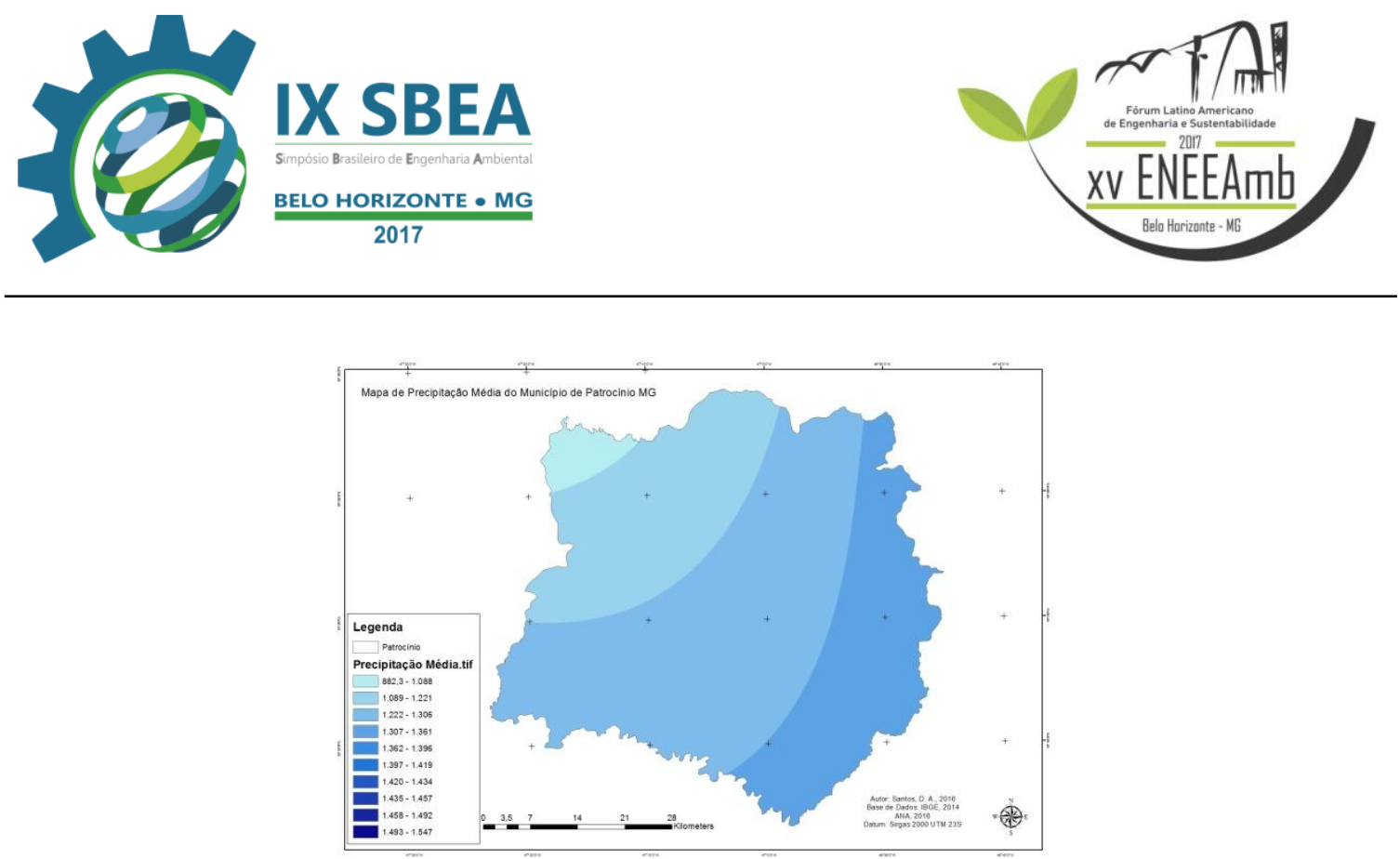

Na figura 03, é possível observar que as menores médias pluviométricas são atribuídas à região norte, latitude oeste do município com uma média de 985 mm/ano, fato que pode ser explicado devido as altas altitudes da região em questão. Já que a mesma se encontra no vale do Alto Paranaíba, tendo sua altimetria média estimada em altas altitudes da região, com uma altimetria média de 742 m (TURCO e BARBOSA, 2008).

\subsection{O balanço hídrico}

A partir das informações a respeito da precipitação e temperatura, é possível verificar a quantidade de água que é extraída do solo por meio de evapotranspiração, e também a quantidade que infiltrada através da precipitação. Sendo assim, temos a quantidade de água retida no solo, também chamado de excedente hídrico e a quantidade necessária para ficar nula a relação, chamada de déficit hídrico.

Tendo como base a Figura 4 observa-se que os maiores excedentes do município de Patrocínio se encontram na região sul, latitude oeste. Como dito anteriormente, há uma relação entre a precipitação e o excedente. Podendo ser verificada através das Figuras 3 e 4 . Nelas se vê que nos locais onde a precipitação é mais intensa, o excedente também é diretamente proporcional a quantidade precipitada. Pode-se observar também que a latitude influenciou no excedente.

Figura 4: Mapa de Excedente Média do Município de Patrocínio - MG 

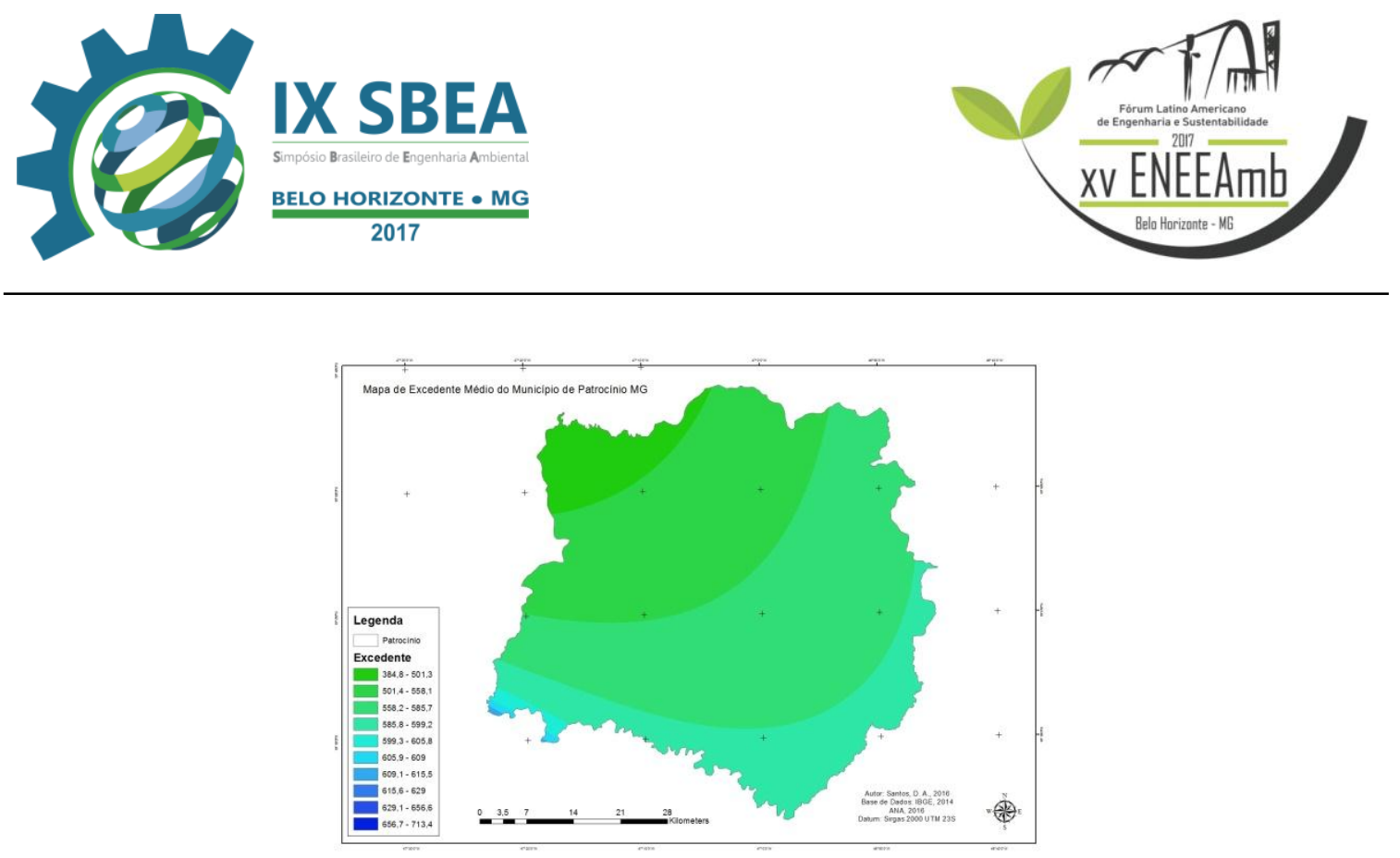

Levando em consideração os dados do Quadro 1, percebe-se que nos meses de novembro a fevereiro houve uma maior precipitação, o que ocasionou uma média elevada do excedente hídrico.

Quadro 1: Quadro de Excedente Hídrico do Município de Patrocínio - MG

\begin{tabular}{|c|c|c|c|c|c|c|c|c|c|c|c|c|}
\hline \multicolumn{10}{|c|}{ Quadro de Excedente Hidrico } \\
\hline Municipio/Mês & Jan & Fev & Mar & Abr & Mai & Jun & Jul & Ago & Set & Out & Nov & Dez \\
\hline Patrocicio & 191,226 & 109,06 & 108,563 & 14,2136 & 2,0679 & 0 & 0 & 0 & 0 & 5,22356 & 53,2005 & 158,402 \\
\hline Irai de Minas & 162,674 & 121,945 & 79,0528 & 40,3659 & 6,12906 & 0 & 0 & 0 & 0 & 1,65827 & 33,9328 & 136,635 \\
\hline Santa Juliana & 184,854 & 101,787 & 94,4522 & 21,1083 & 2,34894 & 0,81754 & 0 & 0 & 0 & 3,68324 & 47,9388 & 151,261 \\
\hline Araxá & 120,316 & 95,5908 & 96,8394 & 24,4335 & 3,29339 & 0 & 0 & 0 & 0 & 8,81455 & 89,8015 & 162,112 \\
\hline Ibiá & 181,94 & 98,3143 & 92,3639 & 18,7931 & 0,84274 & 0 & 0 & 0 & 0 & 0 & 44,9038 & 173,74 \\
\hline Carmo do Paranaiba & 167,241 & 86,7529 & 95,0149 & 16,754 & 0 & 0 & 0 & 0 & 0 & 5,40414 & 72,0708 & 158,804 \\
\hline Monte Carmelo & 193,747 & 111,133 & 80,7493 & 5,27082 & 6,28857 & 0,90057 & 1,51197 & 2,51543 & 2,19282 & 5,20143 & 45,9584 & 148,846 \\
\hline Patos de Minas & 200,04 & 100,662 & 88,7816 & 12,5185 & 0,05175 & 0 & 0 & 0 & 0 & 3,28042 & 71,4463 & 183,825 \\
\hline Sera do Salitre & 206,675 & 121,418 & 125,857 & 14,4534 & 0,07719 & 0 & 0 & 0 & 0 & 3,94694 & 66,2462 & 198,069 \\
\hline Coromandel & 232,08 & 110,004 & 91,7484 & 14,3051 & 0 & 0,74917 & 0 & 0 & 0 & 1,4203 & 63,1658 & 199,911 \\
\hline Média & 184,079 & 105,667 & 95,3423 & 18,2216 & 2,10995 & 0,24673 & 0,1512 & 0,25154 & 0,21928 & 3,86328 & 58,8665 & 167,16 \\
\hline
\end{tabular}

Analisando o déficit hídrico articulado entre os anos de 1991 a 2015, constatou-se que o mesmo é diretamente proporcional a precipitação e ao excedente hídrico. Analisando a Figura 5 percebe-se que a região leste do município tem os maiores níveis de déficit hídrico.

Figura 5: Mapa de Déficit do Município de Patrocínio - MG 

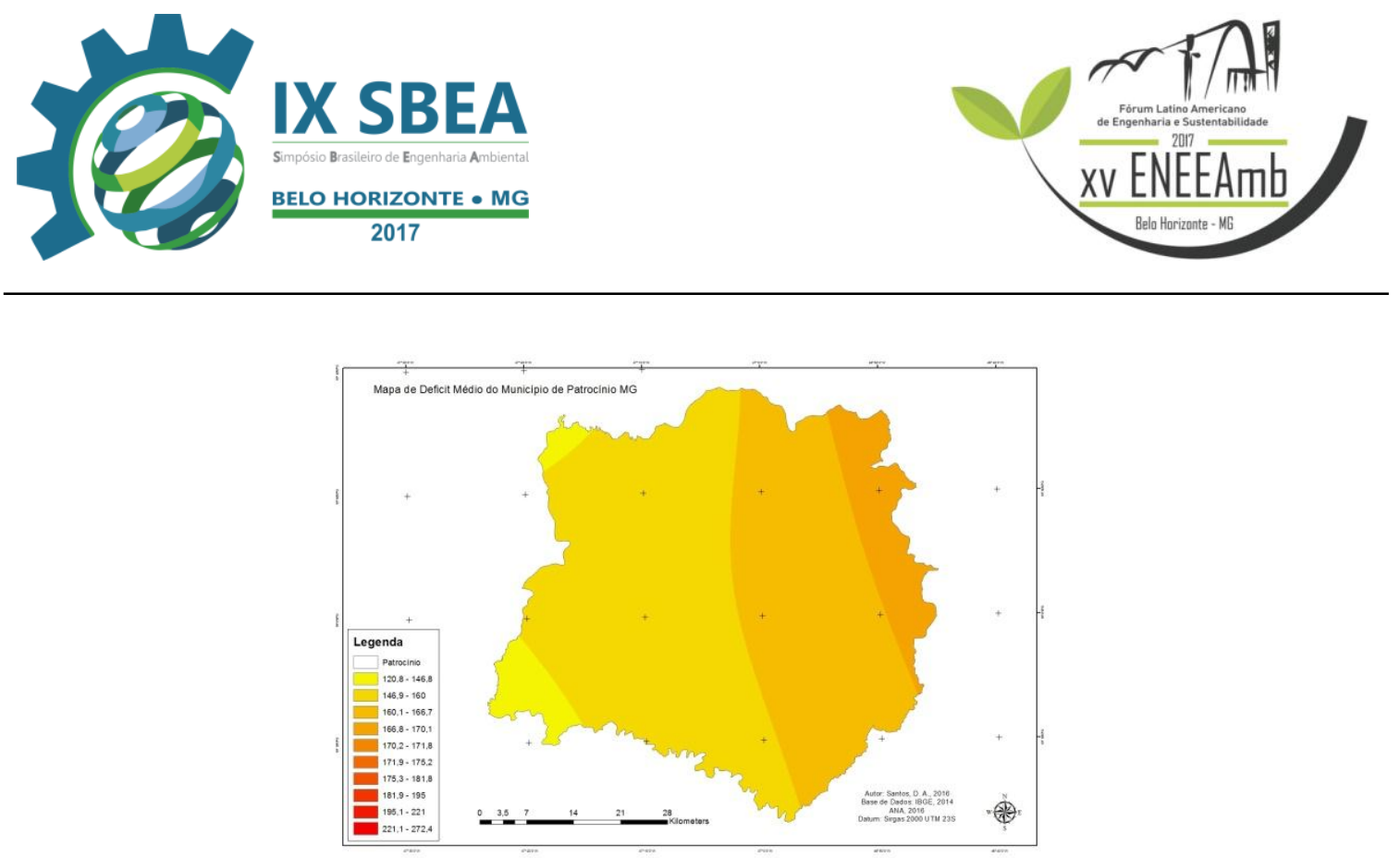

Os dados do Quadro 2 mostram que os meses em que ocorreram os maiores níveis de déficit hídrico são os meses de maio a outubro. Portanto faz-se necessário o uso de técnicas de irrigação durante esses meses, para assim, garantir a produtividade contínua das lavouras.

Quadro 2: Quadro do Déficit Hídrico do Município de Patrocínio - MG

\begin{tabular}{|c|c|c|c|c|c|c|c|c|c|c|c|c|}
\hline \multicolumn{10}{|c|}{ Quadro de Déficit Hidrico } \\
\hline Municipio/Mês & Jan & Fev & Mar & Abr & Mai & Jun & Jul & Ago & Set & Out & Nov & Dez \\
\hline Patrocinio & 0,21297 & 0,22374 & 0,1588 & 2,85271 & 9,72696 & 17,1865 & 32,4247 & 45,1477 & 25,8544 & 15,2419 & 0 & 0 \\
\hline Irai de Minas & 0,09889 & 0,94231 & 0,35455 & 3,98938 & 12,6266 & 20,4457 & 38,6806 & 56,2618 & 50,4645 & 29,7957 & 1,91529 & 0 \\
\hline Santa Juliana & 2,08108 & 1,42044 & 0,19889 & 3,3767 & 9,78052 & 14,5104 & 31,8813 & 47,1072 & 35,9209 & 19,8281 & 0 & 0 \\
\hline Araxá & 3,18963 & 6,699 & 9,73555 & 7,31492 & 14,6861 & 21,7112 & 35,4817 & 54,2046 & 36,4995 & 17,1619 & 0 & 0,71632 \\
\hline Ibiá & 0,00163 & 1,02567 & 0,79989 & 4,37139 & 9,99774 & 17,3614 & 32,9784 & 46,9782 & 34,2975 & 13,0251 & 3,47533 & 0 \\
\hline Carmo do Paranaiba & 0,09917 & 0,66436 & 0,02753 & 4,69829 & 11,2001 & 20,6786 & 36,3478 & 46,1812 & 38,3292 & 20,5472 & 1,07526 & 0 \\
\hline Monte Carmelo & 0 & 1,1747 & 3,45093 & 8,79369 & 19,8625 & 25,2313 & 46,1882 & 61,404 & 49,5412 & 25,2921 & 0,67911 & 0 \\
\hline Patos de Minas & 0,32335 & 1,38436 & 1,69421 & 5,65818 & 20,4746 & 28,7649 & 49,0528 & 66,5427 & 57,0922 & 34,1036 & 3,13449 & 0 \\
\hline Serra do Salitre & 0,91181 & 0,19362 & 0 & 2,11836 & 8,83998 & 15,1346 & 27,383 & 42,4143 & 23,3149 & 10,1247 & 0 & 0,85557 \\
\hline Coromandel & 2,39974 & 3,19722 & 4,20413 & 7,57574 & 18,7645 & 26,7785 & 47,9032 & 67,3853 & 59,2608 & 31,6019 & 3,30717 & 0 \\
\hline Média & 0,93182 & 1,69254 & 2,06245 & 5,07494 & 13,596 & 20,7803 & 37,8322 & 53,3627 & 41,0575 & 21,6722 & 1,35866 & 0,15719 \\
\hline
\end{tabular}

\section{CONCLUSÕES/RECOMENDAÇÕES}

A partir da análise das variáveis apresentadas, verifica-se que as características climáticas vêm se mantendo dentro do aceitável para a produção do café. Se destacarmos os dados referentes aos déficits e excedentes apresentados nas Quadros 1 e 2 vemos que as precipitações ocorrem na época do desenvolvimento do grão, e seu déficit se dá na época da colheita, período no qual o clima está relativamente mais seco, facilitando o processo. 


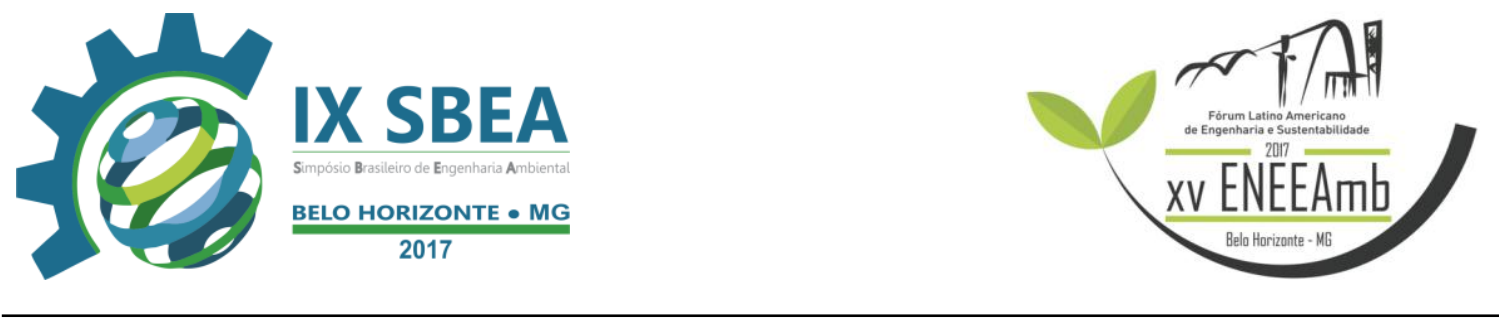

O conhecimento das características e variações climáticas de uma região é essencial para todos os tipos de cultura, pois cada uma requer cuidados específicos. Os conhecimentos acerca do clima podem facilitar as práticas agrícolas, resultando em maior produtividade das lavouras.

Com base nos dados levantados, pelo fato do município de Patrocínio apresentar um índice pluviométrico satisfatório, com precipitações distribuídas ao longo do ano e de forma mais intensa no verão. Pode-se concluir que o clima da Microrregião de Patrocínio torna a mesma adequada para o cultivo de várias culturas, em especial para o café.

\section{REFERÊNCIAS BIBLIOGRÁFICAS}

ANA - Agência Nacional de Águas. Disponível em <http://www.ana.gov.br> acesso em Junho de 2016.

EMBRAPA - Empresa Brasileira de Pesquisa Agropecuária. Disponível em <www.embrapa.br> aceso em Junho de 2016.

IBGE - Instituto Brasileiro de Geografia e Estatística. Censo de 2010. Disponível em ftp://ftp.ibge.gov.br/Estimativas_de_Populacao/Estimativas_2015/estimativa_dou_2015 _20150915.pdf> acesso em Junho de 2016.

IBGE - Instituto Brasileiro de Geografia e Estatística, 2015. Disponível em < http://cod.ibge.gov.br/632> acesso em Junho de 2016.

PEREIRA, A. R.; Angelocci, L. R.; Sentelhas, P. C. Agrometeorologia: Fundamentos e aplicações práticas. Guaíba: Agropecuária, 2002. 478p.

REICHARDT, K. Processos de transferência no sistema solo-planta-atmosfera. Campinas: Fundação Cargill, 1985. 486p.

SANTOS, J. W. M. C. Ritmo Climático e Sustentabilidade sócio-ambiental da agricultura comercial da soja no Sudeste de Mato Grosso. Revista do Departamento de Geografia (USP), v. 1, n. esp., p. 1-20, 2005.

SETZER, J. Atlas Climático e Ecológico do Estado de São Paulo. Comissão Interestadual da Bacia Paraná-Uruguai, 1966. 61p.

THORNTHWAITE, C. W.; MATHER, J. R. The water balance: publications in climatology. New Jersey: Drexel Institute of Technology, 1955. 104 p. 
TURCO, J.E.P., BARBOSA, J.C. Avaliação de duas estações meteorológicas automatizadas, para estimativa diária da evapotranspiração de referência obtida pelo método de Penman-Monteith. Irriga: Brazilian Journal of Irrigation and Drainage. Botucatu-SP, v.13, n.3, p.339-354. 2008. 